\title{
Giddens: da ontologia social ao programa político, sem retorno
}

RENATO P. SAUL*

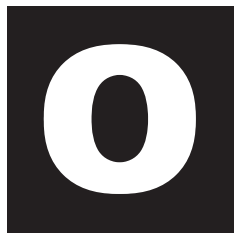

capitalismo contemporâneo é visto por Giddens como um novo modelo de integração social, orientado por laços que se estendem muito além das fronteiras tradicionais das comunidades e das nações, levando em si um novo sentido de organização social e política que desafia as atuais gerações a repensarem as raízes da experiência democrática. Este é o sentido de $A$ terceira via. E também o sentido da teoria social de Giddens.

Se o entusiasmo de Giddens em relação às condições em que se opera a transformação das relações econômicas no plano internacional nos últimos tempos ainda era contido, no momento da formulação do seu

\footnotetext{
" Professor titular aposentado do Instituto de Filosofia e Ciências Humanas da Universidade Federal do Rio Grande do Sul; professor e pesquisador no programa de Pós-Graduação em Ciências Sociais Aplicadas do Centro de Ciências Humanas da UNISINOS.
} 
programa social-democrata, em 1998, isso já não aconteceria um ano depois, quando, juntamente com Will Hutton, edita "On the edge". Afirma ele então: "vivemos um tempo glorioso e assustador". Mais glorioso que assustador poder-se-ia dizer face aos desdobramentos do texto:

Não é nem um período de construção imperial nem do crescimento de ideologias competitivas (...). Nossa geração não enfrenta o risco de guerra global a serviço de bandeira, território ou ideologia. O comércio cresce exponencialmente a cada ano. Os padrões de vida, apesar das marcas da horrenda miséria nos países menos desenvo/vidos, estão não obstante crescendo em todo o mundo. A expectativa de vida cresce globalmente, a mortalidade infantil decresce e as mulheres libertam-se do trabalho doméstico. A economia global aberta é uma preciosa conquista, oferecendo oportunidade, criatividade e riqueza (Hutton \& Giddens, 2001, p. 213-4).

Esta maneira de avaliar os efeitos do processo de globalização econômica em curso e as contradições que definem a sociedade mundial no presente adquire dimensão de galhofa quando Giddens se propõe a examinar a atuação da esquerda na política britânica, atribuindo-lhe uma característica que seria típica das esquerdas de um modo geral: a incapacidade de elas enfrentarem o mundo em que vivem e a ele se adaptarem, bem como a conseqüente descrença na possibilidade de qualquer mudança na "política democrática ortodoxa". Essa característica das esquerdas é definida por ele como "tendência Groucho Marx", referindo-se ao palhaço norte-americano que se tornou famoso pelas frases dominadas pela ambigüidade e pelo contra-senso (Giddens, 2002, p. 10).

Há uma certa correspondência temporal entre a veiculação do conceito de capitalismo global e o debate sobre a necessidade de um terceiro caminho nas articulações políticas nacionais. Dos anos oitenta em diante, tornou-se uma espécie de lugar-comum no pensamento político a veiculação da idéia de que o processo de globalização havia criado uma nova fronteira, afetando não apenas a democracia representativa, o con- 
ceito de soberania e a identidade nacional. Esse processo teria estreitado consideravelmente a margem de manobra macroeconômica, fazendo com que a diferença entre esquerda e direita se reduzisse à maneira como se manipulam receitas e despesas para alcançar macro-resultados. A questão de que tipos de resultados buscar fica posta de lado (Gonzalez \& Hoffmann, 1999), dando margem ao surgimento de diferente concepção de região, o "regionalismo aberto", que circula como característica central do movimento da globalização e de abertura dos mercados nacionais e sua reunião em blocos regionais (ver por exemplo: Bergsten, 1997; Fischer, 1998; Wei \& Frankel, 1998; Konzelmann, 1998).

Na sua atual versão, a terceira via parece ter origens americanas, constituindo-se em resposta tática às derrotas dos democratas daquele país nas eleições de 1980 e 1984. Na manobra para reconquista do eleitorado, a facção conservadora do partido preconizou a necessidade de redirecionamento da atividade partidária, argumentando que a esquerda, ou "liberais-fundamentalistas", estava desatualizada em relação aos desejos do povo americano. Dentro deste contexto, a proposta emergiu, segundo Jeff Faux (1999), como um novo paradigma para a economia global, interpretando, nesse caso, o segmento representativo do mundo dos negócios, em especial do setor financeiro americano. Não parece haver dúvidas de que, a partir dos Estados Unidos, como expressão central do governo Clinton, uma das pretensões básicas da terceira via seria a de representar um novo paradigma político para reger a economia global. Ela emergiu no cenário internacional atual como parceira ideal do paradigma da escolha pública (public choice), hegemônico na regência das estratégias de desenvolvimento nos últimos vinte anos, pelo menos. A versão britânica da terceira via define-se com o governo de Tony Blair e o "novo trabalhismo", tendo Anthony Giddens como um dos seus principais intelectuais orgânicos, senão o principal, pelo menos no início. O programa não foi uma inteira novidade, em termos britânicos. O berço do trabalhismo 
na Grã-Bretanha, a Fabian Society, apresenta-se como a mais antiga vocação socialista da região. Na passagem do século 19 para o 20, os argumentos de sustentação de uma solução ao estilo "caminho do meio" tiveram importantes defensores britânicos, como, por exemplo, Graham Wallas, Leonard Hobhouse e J.A Hobson, sem esquecer os fascistas, na década de 20, e Harold Macmillan, nos anos 30, advogando um capitalismo de face humanizada (ver Rose, 2000, p. 1395; Lukes, 1998, p. 3).

No geral, o programa assume como marco de consideração política o caráter definitivo da economia capitalista, tendo a empresa como elemento central da produção da riqueza. Não deixa de ser extremamente sintomático o fato de que, com sua justificação estabelecida a partir da percepção da complexidade da vida na sociedade contemporânea, a retórica de apresentação da idéia do "novo centro" denote uma contrastante simplificação das condições de realização do projeto. Como a opção socialista deixa de existir, torna-se necessário superar o contraste entre esquerda e direita. A aplicação do esforço político deve ser direcionada no sentido de uma atualização do Estado e de suas relações supra-nacionais, em conformidade com as condições dominantes na economia contemporânea. No manifesto lançado por Antony Blair e Gerhard Schröder, em junho de 1999 em Londres, os objetivos do programa apresentaram como elementos principais uma nova concepção de soberania, tendo como vetores a modernidade e o pragmatismo, estabelecendo o fim da igualdade como objetivo permanente, e do Estado como elemento central da justiça social, promoção do consenso como mecanismo privilegiado da política, a busca da inovação e da iniciativa individual como instrumentos do progresso pessoal e coletivo (conforme Vidal-Beneyto, 1999).

A sociologia de Giddens emerge no interior de um momento de crise e reconstrução de paradigmas que marcam as ciências sociais dos anos 70 e ela mesma é um dos componentes importantes desse processo. Situa-se, na verdade, como representante de uma das tendências principais. Por 
uma parte, sua contribuição define-se pela tentativa de construção de uma síntese de propostas teóricas divergentes, em especial no sentido de superação da competição entre teorias clássicas e contemporâneas. Por outra, ela se inclina pela tendência que parece dominar a cena na atualidade, que é o novo ambiente sociológico, em que a indução pelo mercado funciona como centro ético-político a partir do qual se redefinem as relações correspondentes ao mundo do trabalho. Um dos aspectos mais salientes da perspectiva teórica que assume o mercado como elemento central do acontecer social é a construção de uma teoria do poder, cujas raízes derivam da participação nesse mercado. É como se o "novo ambiente" econômico exigisse um "novo ambiente" sociológico, e nele, como se verá, o fator fundamental será o conhecimento.

Entre a teoria de Giddens e o programa da terceira via há uma articulação bastante estreita. De certo modo, o exame da trajetória de estudos e investigações de Giddens parece mostrar diferentes momentos, tendendo a adquirir um novo rumo nos anos 90, com a publicação de Para além da esquerda e da direita (1994), quando, a partir de considerações sobre as mudanças decorrentes do processo de globalização e de destradicionalização, inclina-se para a exploração das possibilidades políticas da social democracia britânica (Baert, 1998, cap. 4).

A tendência para a vinculação do esforço de construção teórica com a perspectiva de intervenção prática na obra de Giddens, porém, parece datar de momentos bem anteriores. Já no início da elaboração teórica ( $A$ estrutura de classes das sociedades avançadas, de 1972), a noção de estruturação denota a tendência de visualização, não apenas do processo de constituição de um modelo analítico da ordem social, mas de um instrumento de modelagem da ordem social em si. Como afirma na introdução do texto mencionado, identificando a crise da sociologia com a crise do socialismo, manifesta nas suas expressões principais, o marxismo e a social-democracia, as análises ali desenvolvidas encerram pretensões de 
guias de ação imediata (1975, p. 20). No texto de $A$ constituição da sociedade (1984), no qual o seu objetivo de teorização se apresenta em forma acabada, observa-se claramente a intenção de Giddens em transcender um debate epistemológico e afirmar a vocação da teoria social no sentido da construção de uma ontologia social. Diz ele então:

Por mais significativas que elas possam ser, a concentração nas questóes epistemológicas desvia a atenção dos interesses mais ontológicos da teoria social, e é primordialmente nestes que a teoria da estruturação se concentra. Em vez de se preocuparem com disputas epistemológicas e com a questão de saber se qualquer coisa como epistemologia, em sua acepção consagrada pelo tempo, pode ser ou não realmente formulada, sugiro àqueles que trabalham em teoria social se empenhem, em primeiro lugar e acima de tudo, na re-elaboração de concepções de ser humano e de fazer humano, reprodução social e transformação social (p. XVI-XVII).

Os vínculos entre a teoria de Giddens e uma perspectiva mais insinuante em termos de filosofia política adquirem feição mais clara em texto de 1987, dedicado à análise da teoria social contemporânea (Social Theory and Modern Sociology), no qual, dentre as teses levantadas a respeito do futuro desenvolvimento da sociologia, ele evidencia o encaminhamento do esforço da ciência social para um comprometimento maior com programas de transformação da realidade social. Dentre essas teses, destacam-se a relacionada com a tendência de os investigadores sociais redefinirem suas posições a respeito de processos de transformação em larga escala e longo termo, e a que sustenta o progressivo envolvimento da sociologia com programas de reformas sociais e políticas (1987, cap. 3). Isso está posto dentro de um conjunto de observações que buscam mostrar que a teoria social tem a propriedade de constituir e reconstituir o seu objeto, num movimento de permanente transformação de si mesma, que 
se confunde com a transformação de seu objeto.

Aqui se descortina o nexo articulador do texto que anuncia o programa da terceira via em sua vertente britânica. Mais do que uma mera reflexão sobre o impasse diante das condições emergentes na vida política como sugere o subtítulo de $A$ terceira via, ou uma reação contra a apatia e a incapacidade da esquerda para enfrentar a revisão da "ortodoxia" da política democrática, esse texto se constitui num projeto estreitamente comprometido com a teoria social giddensiana. Ele comporta a intenção não apenas de apontar para a solução dos problemas propostos pelo movimento da globalização como também para a fundamentação dessa solução através de sua sustentação num corpo de conceitos cujo sentido é mostrar que ela se encontra na própria dinâmica daquele movimento. Muito embora as noções sociológicas e o conhecimento da vida social não possam ser aplicados imediatamente em planos de intervenção social por parte de órgãos governamentais ou de grupos poderosos, "o impacto prático das teorias sociológicas estão constitutivamente envolvidos no que a modernidade é" (Giddens, 1991, p. 24).

Com o programa de 1998, Giddens propõe-se a dar consistência teórica ao debate desenvolvido a partir da dissolução do consenso que fundamentou o Estado do Bem Estar, cuja crise nos anos 70 é acompanhada por grande movimentação intelectual no terreno das ciências sociais, quando novos paradigmas aparecem como sintomas e resultantes das transformações na economia mundial. Nesse debate, algumas questões aparecem com destaque, concentrando os problemas fundamentais contidos nas controvérsias sobre o futuro de uma política de esquerda atualizada em conformidade com as diretrizes políticas, sociais e culturais da modernidade tardia. Giddens as arrola como dilemas correspondentes às implicações do processo de globalização, da emergência de um novo individualismo marcado principalmente pela inquietação moral dos jovens, pelo esvaziamento do embate ideológico entre esquerda e direita ante de 
uma situação política de outra natureza, pelo surgimento de novas modalidades de atuação política e pela questão ambiental, cuja expressão política logo supera as marcas de suas origens para assumir a expressão de uma nova filosofia de vida. Dentro desse largo espectro de dilemas, a questão nuclear é, em última análise, o processo de reinstitucionalização do mundo do trabalho. O que acontece numa abordagem quase cifrada da questão social, transfigurada em questões de ordem cultural e educacional vertidas a partir dos efeitos do processo de desenvolvimento das novas tecnologias da informação e da comunicação.

Na perspectiva do autor, a resolução dos dilemas da vida na atualidade tem seu núcleo estratégico definido pelo processo de ajuda aos cidadãos para abrir caminho através das "revoluções" do nosso tempo. Ou seja, a globalização, a transformação na vida pessoal e o relacionamento com a natureza. Esse processo implica um novo tipo de relacionamento do indivíduo com a comunidade, através da redefinição de direitos e obrigações. Dois preceitos passam, então, a ser decisivos para a realização desse objetivo. De uma parte, a nova política deverá ser regida pela idéia de que "não há direitos sem responsabilidades". Este preceito questiona as práticas existentes na velha social-democracia que tratava os direitos como "exigências incondicionais", que marcavam um sistema privilegiador de um segmento da sociedade, os beneficiários do welfare. De outra parte, um preceito ético inovador que encoraje a procura ativa do bem-estar deverá ser complementada por um segundo preceito que funcione como garantia da universalidade dos benefícios estatais: "não há autoridade sem democracia" (1999, p. 74-5).

O instrumento de realização destes objetivos é a parceria entre Estado e sociedade civil. Conforme Giddens, a fórmula clássica do welfare state seria o sistema implantado por Bismarck na Alemanha, em pleno século XIX (ibid., p. 121) ou pela União Soviética, onde o Estado "esmagou" a sociedade civil (ibid., p. 95). Na era bipolar, a do "Estado com 
inimigos", é marcada pela pretensão dos social-democratas de ampliá-lo sempre e pela pretensão neoliberal de diminuí-lo ao extremo. Na "velha esquerda", isto é, a social-democracia clássica, a sociedade civil era dominada pelo Estado, que, por sua vez, envolvia difusamente a vida social e econômica. No "tatcherismo", isto é, na época da "nova direita", a sociedade civil apresentava-se como autônoma, e o Estado (ou o governo) estava reduzido à sua expressão menor. A versão thatcherista ou neoliberal da sociedade civil a veria como " um mecanismo auto-gerador da solidariedade social". Na perspectiva do Estado mínimo, o welfare atuaria como um agente de destruição da sociedade civil, enquanto o mercado favoreceria o desenvolvimento de suas virtudes intrínsecas (ibid., p. 18-22).

A era do "Estado sem inimigos", ou seja da terceira via, pretende a reconstrução do Estado, utilizando para isso o próprio movimento da globalização. Fazendo o Estado elemento de resistência à globalização, por um lado, com sua atuação orientada no sentido da "democratização da democracia" e, por outro, aproveitando-se da dinâmica da globalização, para criar uma ordem que não é "nem um superestado nem apenas uma área de livre comércio" (ibid., p. 82). Cabe ao Estado também expandir a esfera pública, buscando maior transparência e abertura em sua esfera de atuação, bem como estabelecer salvaguardas contra a corrupção (ibid., p. 83). O "Estado sem inimigos" deve elevar sua capacidade administrativa para conservar ou recuperar sua legitimidade, usando, nesse sentido, a pressão da globalização para experimentos com democracia local, referendos, júris, etc. (ibid., p. 84-5). Essa legitimidade seria importante para o desenvolvimento de sua capacidade de administração de riscos (ibid., p. 73). Promover uma sociedade civil "ativa" é, assim, preceito básico para a política da terceira via.

A exemplo do que ocorre com o conceito de Estado, que aparece no texto confundido com a noção de governo ou com o ato de governar, o terreno de exame da idéia de sociedade civil é também um campo propí- 
cio a sugerir algumas confusões e ambigüidades. É difícil estabelecer com clareza quais as funções do Estado ou do governo, pois que o uso das noções se alternam e se confundem, não permitindo a identificação de instâncias de poder diferenciadas, ou mesmo ações relacionadas com a atividade de governar. Assim, por exemplo, ao encaminhar o problema da renovação da sociedade civil, dentro da ótica da terceira via, o conceito de governo aparece confundido com a idéia de ação de governar ou de promover o fomento e a renovação da "comunidade" (ibid., p. 79; 89). Apesar de afirmar que não há fronteiras entre governo e sociedade civil, o governo precisa, por vezes, "ser empurrado para o civil" (ibid., p. 90). A noção de sociedade civil aparece associada à idéia de comunidade, que, por sua vez, também aparece diluída em "grupos" não especificados, nos quais seria gerado o "sentimento comunitário". Também o conceito de sociedade civil, neste contexto, parece confundir-se com a idéia de ordem civil: "Uma das principais preocupações do governo deveria ser ajudar a reparar a ordem civil entre esses grupos" (ibid., p. 92-3). Em outros momentos, permanece a confusão em torno do uso alternado de Estado e governo, com a noção de sociedade civil assumindo a conotação de grupos familiares e instituições não-econômicas (Giddens, 2000b, p. 86-7).

De acordo com a sustentação do projeto no texto de 1998, a terceira via vem articulada em torno da proposta de uma "nova economia mista", isto é: uma economia que busca uma nova sinergia entre o setor público e o privado servindo-se do mecanismo do mercado, tendo em mente o interesse público. A noção de interesse público diz respeito, no caso, a grupos de interesse e à orientação das atividades destes para objetivos "comuns". Envolve principalmente as funções sociais desempenhadas pelos "atores sociais" na articulação entre Estado (ou governo) e sociedade civil e na medida em que realize a relação de parceria na busca do interesse maior da sociedade. A sociedade civil e o Estado (ou governo) aparecem como espaços econômicos e políticos funcionais autônomos e desarticulados ou de articulação 
defeituosa. A parceria é, nesse caso, o novo patamar das relações entre Estado (ou governo) e sociedade civil, buscando a efetivação do welfare positivo, contrastando com o anterior welfare negativo, isto é, o da conquista de benefícios por inércia de um sistema equivocado, que premiava igualmente os competentes e os negativamente preparados e incompetentes. A nova economia tem como objetivo precípuo realizar esta parceria e, através dela, resgatar a comunidade. Não a comunidade antiga (de classe), mas a comunidade da auto-organização de grupos de interesse.

A idéia da nova economia mista perseguida pela política da terceira via difere da antiga economia mista que era representada pela separação entre os Estados e os setores privados, uma parte dela pertencente aos poderes públicos estatais. Numa primeira aproximação, essa nova economia, que se define pela sinergia entre público e privado, envolve equilíbrio entre regulação e desregulação e o equilíbrio entre o campo econômico e o campo não-econômico da vida social. Ao contrário da sociedade do welfare negativo, o fluxo dos negócios é livre, e nela não dominam hábitos "inquestionáveis". As esferas dos diferentes mercados apresentam-se como relações altamente dinâmicas, presididas pela relação de risco e responsabilidade (1999, p. 109-10).

A sociedade da nova economia mista deve levar em conta a questão do risco especialmente o lado ativo do risco, isto é, a oportunidade e a inovação (o lado "não ativo" representado por segurança e responsabilidade) (1999, p. 73). O enfrentamento do risco é inerente à atividade empresarial e à força de trabalho. Os agentes devem assumir riscos com responsabilidade, nas esferas dos mercados, governamental, empresarial e do trabalho. O Estado deixa de ser referência para conflitos derivados da desigualdade. A questão da desigualdade se resolve pela eliminação das discrepâncias criadas pela "meritocracia". Ela deve ser conduzida através de reformas que proporcionem oportunidades de formação pessoal e iniciativa individual. O welfare positivo deve voltar-se para a formação de capital 
humano por meio do qual se encaminharia o desenvolvimento da capacidade cognitiva e emocional, elementos decisivos da "inclusão" (1999, p. 113; 127). Deve entender-se que o conflito entre capital e trabalho não existe mais. O que hoje ocorre é uma disputa em torno e dentro de mercados, e o decisivo é ser competente e superar os riscos, ou assumir a incompetência e aceitar o destino que a nova economia reserva para os incompetentes. O trabalhador deve ter o espírito do empresário, da competição e da aceitação de desafios. Ambos são "empreendedores sociais". A empresa é o modelo tanto de competição quanto de criação de riqueza e nele deve inspirar-se a sociedade tanto civil quanto política (Estado ou governo). Ela passa a ser o nervo do "novo interesse público".

O risco é a característica da modernidade tardia ou da sociedade pós-tradicional, termo que Giddens prefere à noção de pós-modernidade, por entendê-la sem precisão. A matriz do risco, que deriva da análise das questões ecológicas como um dos dilemas que dominam o debate em torno das novas direções da social-democracia, serve, assim, de núcleo em torno do qual se estabelecem os elos de ligação entre a teoria social e o programa político. Os elementos componentes da matriz do risco, inovação e oportunidade, segurança e responsabilidade, são os campos representativos dos novos valores da social-democracia renovada e os articuladores de toda a trama que define os novos princípios sociais e políticos que devem caracterizar o novo Estado e a nova sociedade civil.

Na matriz do risco, opera-se a articulação entre o dinamismo da sociedade pós-tradicional e a subjetividade típica do novo individualismo, essencialmente sensível às questões morais da nossa época. Trata-se de um "individualismo institucionalizado" (expressão de Ulrich Beck assumida por Giddens), no sentido de que não se refere mais à manifestação de interesses pessoais como no antigo individualismo, sinal de decadência moral e uma ameaça constante à solidariedade social, mas de um esforço perene pela produção dessa solidariedade e de ampliação da democracia. (1999, p. 46-7). Enquanto na velha social-democracia a questão da respon- 
sabilidade ficava submersa na "provisão coletiva" garantida pelo Estado, o novo individualismo implica o despertar do sentido de responsabilidade que anima a busca do equilíbrio entre o indivíduo e a sociedade.

O exame das relações entre a matriz do risco e os valores que presidem a configuração da sociedade da nova social democracia expõe o fiel deste equilíbrio entre a subjetividade e a dinâmica social da sociedade pós-tradicional: o conceito de segurança ontológica (conceito que parece percorrer todo o conjunto da obra de Giddens e que, significativamente, não é explicitado na exposição da terceira via).

De outro lado, na matriz do risco, fica evidente que o elemento que serve de ligação entre o lado ativo e o lado não-ativo do risco tem a mesma origem da matriz, isto é, a questão ecológica, e tem correspondência também com a estratégica noção de "conservadorismo filosófico". O conservadorismo filosófico implica a combinação entre modernização e conservadorismo e se apresenta como a forma mais adequada para enfrentar a nova combinação entre risco e responsabilidade. Essa combinação de modernidade e conservadorismo é só aparentemente contraditória. Para Giddens ela é a forma pragmática de enfrentar as mudanças decorrentes dos avanços da ciência e da tecnologia e das relações sociais derivadas, que são os elementos fundantes da nova economia mista. Na verdade, na perspectiva do autor, o social se traduz em práticas com extensão espacial e duração temporal que são constituídas a partir de relações de confiança, funcionando esta como base da segurança ontológica (1991, p. 95) que liga as subjetividades às instituições ou às estruturas e aos sistemas. É importante referir que a noção de segurança ontológica parece ser um dos conceitos centrais de toda a teorização social do autor, marcando presença desde seus primeiros trabalhos. A noção desempenha papel decisivo, por exemplo, no desenvolvimento da idéia de dualidade de estrutura e, conforme Giddens, na conseqüente superação da oposição freqüentemente reiterada no debate teórico em sociologia entre ação e 
estrutura. No contexto da reafirmação dos princípios reitores do programa político da terceira via, os conceitos de confiança e segurança ontológica irão desempenhar papel decisivo nas funções de articulação e de garantia da consistência do novo paradigma de ação cívica.

O elemento constitutivo final da engenharia política da terceira via é a atualização do conceito de sociedade civil, que passa a representar o ponto de condensação da agenda de renovação e reconstrução da cidadania (p. 79). Este é o espaço em que se operará a transformação institucional do novo sistema de proteção e segurança, corrigindo a vertente de equívocos acumulados pelo antiga forma de welfare, em que as virtudes do universo do trabalho encontravam-se subordinadas a imperativos assistencialistas totalmente superados pela dinâmica da nova economia mista e pela exigência capital do novo contrato social: a inexistência de direitos sem responsabilidades.

Giddens, em 2000, defendendo-se de seus críticos, volta a reiterar seus argumentos acrescentando, entretanto, alguns aspectos novos quanto à sua fundamentação. Em primeiro lugar, reitera que o debate entre esquerda e direita perdeu substância e grande parte da sua significação para entendimento do que ocorre na sociedade contemporânea. Em segundo lugar, aponta três áreas que emergem como decisivas na esfera do poder: governo (ou Estado), economia e "comunidades" da sociedade civil. A ordem social, a democracia e a justiça social não admitem o predomínio de uma esfera sobre outra. Segue-se a necessidade de elaboração de um novo contrato social fundado no princípio antes mencionado da "inexistência de direitos sem responsabilidade" a ser aplicado a todos, ricos e pobres, empresas ou indivíduos. O quarto ponto refere-se à esfera econômica e, particularmente, à criação da nova economia mista, ancorada na "nova economia da informação" ou "economia do conhecimento". A seguir, considera como objetivo a consolidação de uma "sociedade diversificada" baseada em princípios igualitários. Porém, a terceira via não admite o 
igualitarismo de renda e sim o igualitarismo de oportunidades. E, por último,vem a necessidade de levar a sério a globalização. Ela não tem apenas aspectos negativos. Tem os aspectos positivos, e estes devem ser maximizados pelo programa (Giddens, 2000a, p. 50-4).

A caracterização do movimento que inspira a renovação política contida na proposta da terceira via aparece reforçada nesse texto, indicando com maior detalhe a articulação entre a globalização, as condições econômicas emergentes, sua determinação sobre mudanças na vida cotidiana e o surgimento de uma "cidadania reflexiva". A globalização em curso é diferente de movimentos análogos anteriores (ibid., p. 65). De acordo com Giddens, o fenômeno da globalização, em sua natureza, causas e conseqüências, não se reduz ao mercado global e deve ser entendido também em suas características sociais, políticas e culturais (ibid., p. 68). Não parece haver dúvidas sobre o fato de que o processo econômico em curso está no centro das transformações da sociedade contemporânea. A intensidade do processo de globalização é influenciada diretamente pela revolução na tecnologia da informação, induzindo à globalização da "economia do conhecimento", o que, combinando-se com aspectos mais amplos do processo, gera mudanças na natureza da atividade econômica (ibid., p. 69).

Ao definir as prioridades que a nova política deve promover, ressalta em Giddens a ênfase na questão educacional e do incentivo ao capital humano: "A força chave no desenvolvimento do capital humano deve ser obviamente a educação. Éo principal investimento público para impulsionar tanto a eficiência econômica quanto a coesão cívica" (ibid., p. 73).

É digno de nota o fato de que, através de seu papel no sistema educacional (1999, p. 57) ou como mecanismo eficiente na "redistribuição de possibilidades", substituindo o atendimento através de recursos diretos do welfare negativo (ibid., p. 110-111; 127), o conceito de capital humano parece adquirir uma função teórica importante na reabilitação do conceito de sociedade civil. 
Trata-se, na concepção de Giddens, de uma virtude do processo de globalização que, induzindo uma pressão para baixo, estimularia o desenvolvimento do espírito comunitário nas esferas locais (devolution). Neste caso, o termo comunidade é empregado, esclarece Giddens, não no sentido de recuperação de velhas formas de solidariedade, mas como uma tendência de renovação social e material de grupos, em bairros, pequenas cidades e outras áreas locais mais amplas. A elevação do nível de autoorganização indica a condição reflexiva de uma sociedade, e isso revelaria a inexistência de "fronteiras permanentes" entre governo (ou Estado) e sociedade civil (1999, p. 89-90).

Dentre as ambigüidades e ambivalências de Giddens, a questão da sociedade civil adquire uma dimensão extremamente significativa. No ano de 1973, criticando a teoria do Estado capitalista em Marx, Giddens expressa a sua discordância com a forma em que é sustentada, naquele autor, a relação entre Estado e sociedade (Giddens, 1975, p. 342-ss). Em 1985, afirma que não se utiliza do conceito por ver nele, a partir das análises de Marx, uma fonte de equívocos (2001, p. 93). Em 1994, voltará a insistir na idéia, ao tratar de desenvolver a linha de força de uma política radical (alternativa à social-democracia clássica). Diz ele, argumentando a respeito da necessidade de restabelecer a solidariedade danificada pelas condições vigentes no sistema de mercado sem controles, processo que envolveria certo conservadorismo filosófico e preservaria valores associados até então ao pensamento socialista:

É importante não interpretar isso no sentido da idéia de uma revitalização da sociedade civil, que goza de tanto prestígio entre certos setores da esquerda. $O$ conceito de uma "sociedade civil" intermediária entre indivíduo e o Estado é (...) suspeito quando se aplica às condições sociais atuais. Hoje devemos falar mais propriamente de reordenamento das condições da vida 
individual e coletiva, o que indubitavelmente produzirá novas formas de desintegração social, porém também oferecerá novas bases para gerar solidariedades (2000b, p. 81).

Outros textos publicados anteriormente a $A$ terceira via, de grande importância para o encaminhamento de uma discussão em torno do papel ou de uma crítica do conceito de sociedade civil sequer o mencionam (veja-se, por exemplo, Modernização Reflexiva, texto datado de 1995, e Affluence poverty and the idea of a post-scarcity Society, datado de 1996).

Ao longo da exposição do programa da terceira via, no entanto, o conceito de sociedade civil vai adquirindo um sentido estratégico. E, sem que uma explicação razoável seja dada, opera-se uma espécie de transformismo teórico do conceito antes tido como "equívoco" ou "suspeito", passando a constituir-se em elemento básico do seu programa político, com a função de constranger o poder dos mercados e do governo (1999, p. 88; 2000a, p. 64).

Alguns conceitos desenvolvidos por Giddens, no entanto, parecem desempenhar função crucial nessa operação, além do de capital humano. São, entre outros, os conceitos de política da vida, de estilo de vida e política regenerativa. O conceito de política da vida vem contrapor-se ao conceito de política emancipatória, típica da esquerda tradicional. Esta concepção representaria uma perspectiva política estreitamente vinculada à idéia de emancipação, isto é, à pretensão de mais liberdade - em vários sentidos -, de luta contra a opressão, de defesa contra as privações materiais, etc. A política da vida significaria não uma política de oportunidades, mas de um estilo de vida, de discussões e lutas e de conformação de novo modo de decisão política. Essas noções derivam de mudanças, tanto em instâncias sociorganizacionais quanto de destino pessoal, desencadeadas no interior do movimento de reflexividade institucional, de desatrelamento 
das relações sociais em virtude dos sistemas abstratos e pela interpenetração entre o global e o local. Mudanças que correspondem a transformações éticas envolvidas na conformação da modernidade tardia (Giddens, 1996, p. 371-2; 1997a, cap. 7; 2000a, p. 40; 2000b, p. 83-4).

O conceito de life-style bargaining aponta na direção de negociações para o estabelecimento de compromissos sobre recursos de um modo geral, baseadas em coalizões de políticas da vida entre diferentes grupos. Existem formas de barganha diversas, dentre as quais, a que atua no campo do gerenciamento dos riscos, a relacionada com os acordos em torno de temas econômicos, como salários e contratos, e a barganha que funciona no terreno do debate sobre questões ecológicas (1996, p. 374-5). O conceito de política regenerativa é uma forma de exercício de reflexividade social que se opera no espaço que vincula o Estado à mobilização reflexiva da sociedade em seu conjunto: "A política regenerativa é uma política que tenta criar as condiçôes de possibilidade para que indivíduos e grupos sejam capazes de fazer coisas - ao invés de esperar que Ihes façam as coisas no contexto das preocupaçôes e objetivos sociais globais"(2000b, p. 85-6).

Resumindo as transformações que se operaram na vida econômica nos últimos tempos, Giddens observa que, na velha economia, a manufatura dominava o campo de articulações entre manufatura, finanças e conhecimento. Na nova economia, a economia global, o setor de finanças adquiriu maior autonomia, submetendo os setores produtores. O conhecimento se tornou menos subserviente à manufatura, na medida em que se fez questão-chave da produtividade. Os mercados financeiros cresceram de forma diversa, guiados pela crescente complexidade do conhecimento que envolve seu funcionamento. Em tais condições, o controle do capital manufatureiro e a regulação dos mercados financeiros permaneceriam sendo as tarefas mais importantes dos governos de centro-esquerda. Mas, na medida em que uma outra dimensão da economia se foi tornando ainda mais importante, o governo necessita construir uma "base de conheci- 
mento" que liberte o potencial da economia fundada na informação (2000a, p. 72-3). Essa base é constituída fundamentalmente por trabalhadores polivalentes, cujo saber "é a propriedade mais valiosa que as empresas dispõem", e a inovação e a busca de "nichos de mercado", tendo em vista que o ciclo dos produtos é muito mais rápido hoje do que nos tempos da velha economia (ibid., p. 69-70). É no contexto de devolution, isto é, no processo de indução da autonomia local pelo movimento de globalização (ibid., p. 62; 153) que conceitos como life polítics e life-style bargaining, compreendendo estilos de atuação política vivenciados nas comunidades, dão sentido mais adequado à concepção giddensiana de sociedade civil como uma das três faces do poder na sociedade contemporânea, ao lado do mercado e do governo (Estado) (ibid., p. 51). É ainda dentro da perspectiva desta "pressão para baixo" que a questão da inovação se revela em potência plena como parte central da economia baseada no conhecimento, como produto de redes e projetos realizados em processos de colaboração (ibid., p. 79).

A reconfiguração do conceito de sociedade civil no contexto da análise da estratégia política, econômica e social da terceira via tem como matéria prima a combinação entre a vocação para a vida cívica dos pequenos grupos (1999, p. 91-3) e a educação, compreendida na perspectiva de "capital humano". A este arranjo o conceito de "capital social" vem conferir dimensão extraordinariamente operativa em termos teóricos e, evidentemente, em termos práticos. A noção de capital social combinada com esses conceitos joga papel decisivo na dinâmica do processo de "democratização da democracia", tal como Giddens costuma enfatizar nos textos $A$ Terceira Via, Mundo em Descontrole e Terceira Via e seus Críticos.

Em conformidade com Giddens, a promoção do capital social é indispensável à economia do conhecimento. Neste sentido, a constatação das virtudes constitutivas do novo individualismo que acompanha a globalização agrega substância à sua tese. Ele não é refratário à coopera- 
ção ou à colaboração, como se verificava na situação anterior. Pelo contrário, a cooperação seria estimulada por ele, muito mais do que a hierarquia. E aqui as propriedades do capital social, aparentemente um conceito recém-incorporado ao arsenal de argumentos de sustentação do programa, surgem de modo providencial na fusão das diferentes dimensões do projeto: "o capital social refere-se às redes de confiança que indivíduos podem estabelecer para apoio social, como o capital financeiro pode ser acumulado para investimento. Como capital financeiro, capital social pode ser expandido - investido e reinvestido". Ademais, ou melhor, em conseqüência desta característica intrínseca, ele é visto como de "fundamental importância na sociedade civil", tornando possível a civilidade cotidiana, que é fator de crucial importância para uma "efetiva vida pública". No contexto da nova economia, "ele tem uma outra específica significação. Éa base das redes que tem papel relevante na inovação" (2000a, p. 78).

É importante ressaltar a maneira como o conceito de capital social aparece na análise do programa da terceira via. A primeira referência explícita ao conceito parece ocorrer no texto de $A$ terceira via e seus críticos. Isso se verifica de duas maneiras. Num primeiro momento, a noção de capital social é mencionada lembrando James Coleman como responsável pela sua popularidade e, num outro momento, ele vem mesclado a uma tentativa de caracterização das novas relações sociais estimuladas a partir da difusão das novas tecnologias da informação, aproximando-se bastante das noções desenvolvidas por Robert Putnam.

$\mathrm{Na}$ análise realizada por James Coleman, como, por exemplo, na exposta em artigo datado de 1988, o conceito de capital social se define fundamentalmente pela sua função, isto é, como entidades e aspectos da vida social que facilitam as ações e interações de atores ou grupos. De acordo com Coleman o capital social não é uma entidade singular, mas um composto de entidades que possuem dois elementos comuns: "eles consistem em aspectos das estruturas sociais e eles facilitam certas ações dos 
atores dentro da estrutura, sejam pessoas ou atores corporativos, dentro da estrutura" (1988, p. 98).

Coleman buscava, ao que tudo indica, estabelecer uma correção de curso na "teoria da troca", baseada em postulado central da teoria econômica a respeito da tomada de decisão individual e racional (1964, p. 166), que, no final dos 50, adquiria força na teoria sociológica, em especial na sociologia americana. Ele parece pretender então dar maior consistência à teoria da escolha racional, tal como vinha sendo passada para dentro da sociologia, limitada em sua capacidade de socialização. De acordo com ele, impõe-se mostrar, através da noção de capital social, a articulação entre a escolha racional e o contexto social em que ela se verifica. Assim, ele mostra como a ação racional está contida numa estrutura social que a constrange e condiciona (1988, p. 97-98).

A outra vertente que parece inspirar Giddens, embora não seja citada explicitamente, é a do teórico dos valores cívicos e comunitários, Robert Putnam, que, em 2001, foi considerado por órgãos da imprensa britânica, como o "novo guru intelectual" de Tony Blair. Com Putnam, cujas contribuições parecem inspiradas em Coleman, a noção de capital social tende a dar um novo rumo à discussão da noção de sociedade civil, fazendo das atividades comunitárias e seus desdobramentos na manifestação do sentimento cívico a pedra de toque do processo de desenvolvimento econômico.

Giddens procura explorar a noção de capital, a partir da caracterização das redes de confiança típica das empresas industriais de vanguarda da nova economia, ou da economia do conhecimento, como de diferente natureza das redes da velha economia, em que a confiança não era primariamente uma "confiança ativa", ademais de estarem as relações enredadas em rotinas e instituições inflexíveis e envolverem diferentes formas de apadrinhamento e corrupção. Na emergente sociedade do conhecimento, as relações de confiança seriam abertas e negociadas ativamente. Por sua fluidez e diversidade, as novas redes de confiança assegurariam um fluxo 
contínuo de inovações. Daí resultaria uma diferença decisiva na dinâmica do próprio sistema de desenvolvimento tecnológico: na velha economia a inovação era resultado de um processo separado de investigação, desenvolvimento e produção. Na economia baseada no conhecimento, as inovações fluem de redes e processos de colaboração entre firmas (2000a). A difusão da tecnologia da informação seria a principal responsável na estimulação das articulações dessas redes de confiança e colaboração.

Essas duas vertentes na exploração do conceito de capital reforçam a perspectiva privilegiadora do campo econômico que marca os textos de sustentação do programa da terceira via. Dentro dessa perspectiva, ressalta a valorização da teoria da troca. As relações sociais são pensadas sempre em termos de escolhas e de decisões que se processam num intercâmbio de habilidades e recursos e numa relação de equilíbrio entre aspectos ativos e não-ativos do risco. Desse modo, na medida em que o risco assume a função de base da vida política, toda a sua dinâmica se define a partir da exploração dos "capitais individuais" e de sua combinação em empreendimentos coletivos orientados para o bem comum.

Duas questões parecem desdobrar-se a partir daí. Primeiramente é oportuno lembrar que, no contraste entre perfis de risco, traçados por Giddens em Conseqüências da Modernidade, a difusão da confiança desempenha papel central nas sociedades modernas. Depois, deve-se considerar que todo o discurso de Giddens relacionado com a caracterização da modernidade recente e do processo de destradicionalização que a globalização implica (ver, por exemplo, Giddens, 1991 e 1997), sugere a verificação de uma transformação substancial na teorização sobre o sistema econômico a partir da dinamicidade de uma economia fundada nas novas tecnologias, cuja característica principal é a criatividade e a inovação. De certo modo, aqueles conceitos sugerem uma analogia entre as posições de Giddens sobre a nova economia e a perspectiva da destruição criativa desenvolvida por Joseph Schumpeter (1952, p. 82-4). Este, criticando os economistas por não perce- 
berem um aspecto crucial do capitalismo, sustentava que o problema usualmente enfocado por eles era a maneira como o capitalismo administrava as estruturas existentes, quando a questão relevante era como ele as criava e como as destruía. Assim, Schumpeter, não só apontava para uma característica essencial do capitalismo, mas também procurava mostrar que a criatividade era uma atividade econômica. Mas é importante realçar que essa promoção da criatividade e sua inserção na esfera econômica se verificam via introdução de novas tecnologias, promovida por empreendedores sociais e daí se estendem às transformações nas esferas da vida política, da vida social e da vida cultural.

A analogia com a interpretação schumpeteriana se reforça na medida em que ela serve também para definir o caráter evolutivo do sistema capitalista. O conflito entre esquerda e direita surge em Giddens como algo que diz respeito à epoca do Welfare State ou à época em que se entendia que o capitalismo poderia ser superado e, apoiando-se em afirmativa de outro autor, o modelo em que a discussão se dava sobre concepções superadas de capital e trabalho (2000a, p. 39; 41). Este elo com a vocação evolucionista da teoria social não parece ser acidental, uma vez que guarda relação estreita com a tradição trabalhista inglesa dos primeiros anos do século 20 (ver a propósito Studholme, 1997).

Nesse contexto, concorrem algumas tendências que, tudo parece indicar, têm a máxima significação para o curso da questão social hoje em dia e, por via de conseqüência, para a questão dos direitos humanos.

Um primeiro ponto diz respeito à crise que envolveu o Estado intervencionista, cuja crise fiscal comporta, além de uma mudança de modelo de política econômica, a mudança de diretrizes teóricas no terreno da economia, com a preponderância da visão fundada na teoria neoclássica e a ênfase nos aspectos sistêmicos da vida econômica. Representa, ademais, uma transformação radical no terreno das alianças políticas de sustentação e legitimação do Estado, pelo menos no que respeita 
aos países de maior desenvolvimento econômico. No período de grande prosperidade do capitalismo, nos anos que se seguiram à Segunda Guerra Mundial, graças a essas alianças, os contigentes assalariados desses países conseguiram avançar em conquistas materiais e políticas importantes. A crise marca um retrocesso decisivo nessas conquistas.

Os anos 80 mostram uma reviravolta decisiva quanto ao debate em torno do mundo do trabalho, com o tema dos direitos humanos adquirindo sintomaticamente especial projeção no mundo ocidental. O final dos anos 80 parece ser o momento crucial dessa mudança. Duas ocorrências são decisivas na definição da nova visualização do tema: o centenário da Revolução Francesa e o colapso do sistema soviético, precedido pela crise da utopia comunista e do marxismo, nos anos 70. Essas duas ocorrências patrocinam o ambiente ideológico para a difusão de uma reorientação da questão dos direitos humanos colocados em um novo cenário, em cujo centro figuram a liberdade e a dignidade individuais, com o mercado funcionando como locus privilegiado de socialização e de realização da emancipação do homem.

Não é obra do acaso o fato de que, nessa conjuntura, verifique-se uma espécie de renascimento do conceito de sociedade civil como elemento de destaque nas análises sociológicas. Por uma parte, o conceito se torna uma necessidade de ordem tática, como uma espécie de refúgio de uma intelectualidade que tem que abandonar suas posturas de orientação científico-revolucionárias e partir para uma posição defensiva dentro dos muros da ordem civil. É o momento em que os textos de Antonio Gramsci em torno da questão da hegemonia e da sociedade civil vivem momento de excepcional atualização, em grande parte servindo de instrumento da preservação de um espaço de manobra de significativo contingente de intelectuais em busca da sobrevivência política. Esse momento também marca o desligamento do conceito de sociedade civil com seus compromissos teóricos de origem naquele autor. De outra parte, a própria con- 
cepção liberal de sociedade civil experimenta uma reformulação importante. Em conformidade com a análise de Peter Gowam, à idéia liberal de sociedade civil correspondia uma função política fundamental, cabendoIhe assegurar que a gestão pública fosse controlada por uma ampla discussão e pelo exercício da pressão por parte da cidadania através de redes de instituições civis. Em conformidade com a visão neo-clássica da economia que alimenta o paradigma do Estado mínimo, a sociedade civil deverá compor um sem número de instituições caritativas e grupos de auto-ajuda, sob o patrocínio de grandes empresas, e a organização de entes semi-públicos encarregados de administrar atividades dos consumidores individuais, política e civilmente passivos (2000, p. 318-9).

Esses pontos compõem a infra-estrutura do projeto de Anthony Giddens. A lógica que orienta o programa é, de acordo com ele, a que se baseia nas conseqüências de 1989, quando a política orientada por posições de "esquerda" ou de "direita" perdem a sua capacidade interpretar os acontecimentos da vida contemporânea. Dentro dessa lógica, a crise do Estado do Bem Estar e de suas instituições mais do que uma crise fiscal, como freqüentemente é interpretada, é uma crise do gerenciamento do risco. No entender de Giddens, o Estado de Bem-Estar foi um sistema desenvolvido em torno de riscos externos (não manufaturados) a que as pessoas estavam submetidas dentro de determinadas condições de vida em geral. Na medida em que muda a natureza do risco, isto é, numa era em que domina a incerteza manufaturada decorrente da intervenção humana na natureza e da aceleração das mudanças da vida social, as instituições do Estado de Bem-Estar entram em colapso.

O conceito de política da vida ganha expressão nesse contexto, como núcleo de um novo processo de tomada de decisões a partir do qual, incorporando a "destradicionalização do mundo da incerteza manufatura$d a^{\prime \prime}$, processa-se a crítica positiva do Estado e se realiza a reorganização das instituições voltadas para o bem-estar. 
O conceito de política da vida e o estilo de vida política correspondente, que substitui a velha noção de "papel social", atua como ponte para a reintrodução do conceito de sociedade civil, que adquire, no programa da terceira via, um valor central. O conceito de sociedade civil exerce no esquema de Giddens a função de lubrificante de todas as esferas prioritárias do programa econômico proposto (nomeadamente: a educação, os incentivos, a cultura empresarial, a flexibilidade, a difusão dos efeitos e o capital social). A sociedade civil passa a ser a fonte de legitimidade e de regulação da vida de um modo geral. Na comunidade assenta a identidade, seja ela familiar, étnica, religiosa ou nacional. Mas as comunidades apresentam problemas bem conhecidos. Muitas vezes elas alimentam identidades políticas com capacidade para produzir divisões e desintegração social. O exclusivismo dificulta a reconciliação de princípios de tolerância e diversidade, tão indispensáveis a uma sociedade civil "efetiva": "É para a sociedade civil mais que para a comunidade que devemos voltar-nos como um elemento essencial da terceira via" (2000a, p. 63-4).

Duas questões emergem daí com destaque. Parece perfeitamente clara, na formulação de Giddens, a consolidação do paradigma de ciência social como instrumento epistemológico privilegiado (ver, por exemplo: Giddens, 1991, p. 19-25; 47; 1997, p. 73-4). Esse paradigma pode ser identificado através do modo de entender quem são os atores do processo político e da forma em que se projeta a sua atuação para alcançar o objetivo social do projeto, o "welfare positivo". Seu caráter positivo-normativo está evidente na definição dos atores do processo econômico e político. Em segundo lugar, e como corolário do primeiro ponto, vislumbra-se a perspectiva de uma solução política muito próxima da democracia econômica de estilo schumpeteriano, em que as condições psicossociais dos atores definem o seu destino, a inclusão. No conjunto, o projeto sustenta o fim da igualdade como objetivo permanente e o do Estado como elemento central da justiça social. A promoção do consenso é o mecanismo privi- 
legiado da vida política. A busca da inovação e da iniciativa individual e grupal são pensados como elementos decisivos do progresso pessoal e coletivo. O risco é a condição do jogo político, e o sucesso depende das capacidades emocionais e reativas dos indivíduos e dos grupos. A confiança é o suporte deste arranjo de riscos e oportunidades, cuja regra é "não há direitos sem responsabilidades", e o investimento social privilegiado na política da terceira via deve ser orientado para a promoção do capital humano em substituição do sustento econômico típico do welfare negativo, que estimulava a ignorância e a ociosidade.

É importante assinalar que a presença destas duas lógicas, conjugadas na construção da estratégia do desenvolvimento econômico e social, acentua a suspeita, de uma parte, da presença de uma vocação autoritária embutida no projeto. De outra parte, a sua formulação alimenta o espectro de uma superciência social cujo objetivo é a junção harmoniosa da liberdade, da eficiência, do egoísmo e da utilidade. O projeto político de Giddens e do Novo Trabalhismo britânico consagra, de forma inequívoca, como novo cenário da justiça social, a democracia articulada a partir do mercado, onde o potencial político da questão social transmuta-se na capacidade individual de tomada de riscos, tendo por substrato o capital social.

Não deixa de ser curioso o fato de que Giddens eleja como indicador da complexidade da análise da realidade social contemporânea e de base de seus argumentos na confecção do livro $A$ constituição da sociedade, um pronunciamento "aparentemente inócuo" de Karl Marx, que reproduzo tal como aparece na edição em português, de 1989: "os homens [permitamnos dizer imediatamente: os seres humanos (AG)] fazem sua própria história, mas não a fazem como querem; não a fazem sob circunstâncias de sua escolha...". A esta citação, Giddens agrega: "Bem, assim acontece" (p. XVII).

$\mathrm{Na}$ verdade, nem sempre assim acontece.

A íntegra da frase de onde é extraída a citação vem reproduzida no pé da página, ali constando a sua versão original em alemão e a correspon- 
dente tradução. Essa frase, com a qual Giddens quer mostrar a necessidade de transcender as fronteiras das disciplinas para incorporar à teoria social o esforço de reelaboração da própria concepção de ser humano e de fazer humano, de reprodução social e de transformação social (p. XVI-XVII), termina de modo a reiterar o conteúdo principal do excerto contido no corpo da introdução. Assim:

A tradição de todas as gerações mortas aflige como um pesadelo o cérebro dos vivos. E é precisamente quando parecem ocupados em revolucionar-se a simesmos è̀̀ coisas, em criar algo que nunca existiu, justamente nessas épocas de crise revolucionária, os homens chamam angustiadamente em seu socorro os espíritos do passado (Karl Marx, 18 de Brumário de Luis Bonaparte, apud Giddens, 1989, p. XVII).

Algumas linhas adiante, na seqüência do texto de $O 18$ de Brumário, em parte não reproduzida naquela nota, entretanto, vemos contrariado o sentido de circularidade histórica que Giddens atribui ao pensamento de Marx reproduzido. Aquelas "conjurações dos mortos na história universal" podem apresentar diferenças decisivas. Depois de mencionar vários exemplos de situações discrepantes, Marx observa que nelas,

a ressurreição dos mortos servia para glorificar as novas lutas e não para parodiar as antigas, para exagerar na fantasia a missão traçada e não para retroceder ante seu cumprimento na realidade, para encontrar o novo espírito da revolução e não para fazer vagar outra vez seu espectro (Marx, 1973, v. 1, p. 410).

Ademais do contraste evidente entre a análise histórica de Marx e a ontologia social proposta por Giddens, o texto escolhido como fonte de inspiração de sua extensa reflexão, quando examinado na sua integralidade, coloca em julgamento o próprio esforço do sociólogo inglês em construir a alternativa crítica da "política democrática ortodoxa". A referência a Marx 
funciona, na realidade, como uma espécie de catarse do autor frente às concepções políticas de direita e de esquerda, ambas ultrapassadas, na sua visão, pela velocidade das mudanças engendradas a partir do desenvolvimento das novas tecnologias e pela difusão de seus efeitos na vida econômica, social e cultural. Em última instância, o programa político de Giddens corresponde à tentativa de consolidar uma concepção sistêmica de sociedade, em que domina a perspectiva autopoiética, presente em seus escritos, pelo menos, desde os anos setenta, em New rules of sociological method (1976) e Central problems in social theory (1979, de um futuro que é o presente enriquecido pela reflexividade, ou seja, de um futuro que representa a ruptura com o passado sem ruptura do presente. Processo que é traduzido nos seus escritos pelo conceito de destradicionalização e, veladamente, pelo seu irmão de sangue, o conceito de destruição criativa.

\section{Referências}

BAERT, Patrick. Social theory in the twentieth century. New York: New York University Press, 1998.

BERGSTEN, C. Fred. Open regionalism. Institute for International Economics, Working Paper 97-3, 1997.

FAUX, Jeff. Lost on the third way. Dissent, v. 46, n. 2, N. York, Spring 1999, p. 67-76.

FISCHER, Bernhard. Globalisation and the Competitiveness of Regional Blocs. Intereconomics, v. 33, n. 4, jul/aug 1998, p. 164-172.

GIDDENS, Anthony. A estrutura de classes das sociedades avançadas. Trad. Márcia B. de Mello Leite Nunes. Rio de Janeiro: Zahar, 1975.

GIDDENS, Anthony. Social problems in social theory. Berkeley, Los Angeles: University of California Press, 1979.

GIDDENS, Anthony. Social theory and modern sociology. Stanford, Califórnia: Stanford University Press, 1987. 
GIDDENS, Anthony. As conseqüências da Modernidade. 2a . ed. São Paulo: UNESP, 1991.

GIDDENS, Anthony. Modernidad y identidadel yo: El yo y la sociedad en la época contemporánea. Trad. José Luis Gil Aristu. Barcelona: Peninsula, $1997 a$.

GIDDENS, Anthony. Modernização reflexiva: política, tradição e estética na ordem social moderna. São Paulo: UNESP, 1997b.

GIDDENS, Anthony. Affluence, Poverty and the Idea of a Post-Scarcety Society. Development and Change, v. 27, 1996, p. 365-377.

GIDDENS, Anthony. A terceira via: reflexões sobre o impasse político atual e o futuro da social-democracia. Rio de Janeiro/São Paulo: Record, 1999.

GIDDENS, Anthony. The Third Way and its Critics. Cambridge: Polity Press, 2000a.

GIDDENS, Anthony. Mundo em descontrole. Rio de Janeiro, São Paulo: Record, $2000 b$.

GIDDENS, Anthony. En defensa de la Sociología. Trad. Jesus de Alborés. Madrid: Alianza Ed, 2000c.

GIDDENS, Anthony. O Estado-nação e a violência. Trad. Beatriz Guimarães. São Paulo: EdUSP, 2001.

GIDDENS, Anthony. Where now for New Labor? London: Polity, 2002, p. 10.

GONZALES, Felipe \& HOFFMANN, Stanley. European Union and Globalization. Foreign Policy, n. 115, summer 1999, p. 28-43.

GOWAN, Peter. La apuesta por la globalización: la geoeconomia y la geopolítica del imperialismo Euro-Estadounidense. Madrid: Akal, 2000.

HIRST, Paul e THOMPSON, Grahame. Globalização em questão. Trad. Wanda Caldeira Brant. Petropolis: Vozes, 1998.

HUTTON, Will \& GIDDENS, Anthony. On the edge. London: Vintage, 2001. 
Sociologias, Porto Alegre, ano 5, no 9, jan/jun 2003, p. 142-173

KONZELMANN, Suzanne J. Regionalization and Labour Market Interdependence in East and Southeast Asia. Journal of Economic Issues, v. 32 (4), Dec. 1998, p. 1174-1177.

LUKES, Steven. Left down the middle. The Times Literary Supplement, september 25, 1998, p. 3-4.

MARX, Karl. El dieciocho de Brumário de Luis Bonaparte. In MARX, k. \& ENGELS, F., Obras escogidas. Moscow: Ed. Pregreso, 1973, v. 1, p. 408-498.

ROSE, Nikolas. Community, citizenship, and the third way. The American Behavioral Scientist, v. 43, Issue 9, Jun/Jul 2000, p. 1395-1411.

SCHUMPETER, Joseph. Capitalism, socialism and democracy. 4a. ed. London: George Allen \& Unwin Ltd, 1952.

STUDHOLME, Maggie. From Leonard Hobhouse to Tony Blair. A Sociological Connection? Sociology, 31 (3), august 1997, p. 531-547.

VIDAL-BENEYTO, José. La social-democratie privatisée. Le Monde Diplomatique, juillet, 1999.

WEI, Shang-Jin \& FRANKEL. Jeffrey A. Open regionalism in a world of continental trade blocs. International Monetary Fund. Staff Papers - International Monetary Fund; Washington, Sep 1998. 


\section{Resumo}

O texto examina as relações entre a teoria social de Anthony Giddens e o programa da terceira via que marca a inserção do autor como intelectual do Novo Trabalhismo britânico. O objetivo é mostrar que, na construção desse programa, os elementos centrais da crítica da "política democrática ortodoxa" tem sua fundamentação naquela teoria social. O processo de globalização é visto pelo autor como um novo modelo de integração social orientado por laços que se estendem muito além das fronteiras tradicionais das comunidades e das nações, levando em si um novo sentido de organização social e política que desafia as atuais gerações a repensarem as raízes da experiência democrática. Esse é o sentido do programa da terceira via e também o sentido da teoria social de Giddens. Num plano mais geral, observa-se que a teoria e seu programa político delineiam-se no interior da tendência que parece dominar a cena na atualidade, a percepção de um novo ambiente sociológico, onde a indução pelo mercado domina como centro éticopolítico a partir do qual se processa uma ampla redefinição das relações sociais, políticas e econômicas, tanto no plano local quanto no plano global.

Palavras-chave: ontologia social, teoria sociológica, globalização, destradicionalização, terceira via. 